\title{
Serine/Threonine-Protein Kinase Nek10
}

National Cancer Institute

\section{Source}

National Cancer Institute. Serine/Threonine-Protein Kinase Nek10. NCI Thesaurus. Code C90326.

Serine/threonine-protein kinase Nek10 (1172 aa, 133 kDa) is encoded by the human NEK10 gene. This protein plays a role in phosphorylation of proteins. 